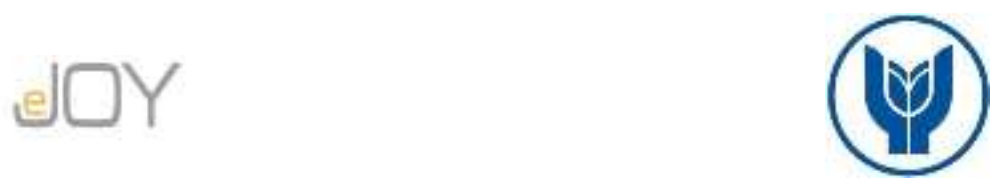

Eriş, E., D., Özmen, Ö., N., T., Bayam, B., Y. / Journal of Yasar University, 2020, 15/58, 259-269

\title{
Mavi-Beyaz Yaka Dönemi Bitti mi? İş Yaşamında Alternatif Yaka Renkleri Üzerine Bir Değerlendirme ${ }^{1}$
}

\section{Is Blue-White Collar Era Over? An Overview About Alternative Collar Colors in Workplace}

\author{
Engin Deniz ERİŞ, Dokuz Eylül Üniversitesi, Türkiye, engindeniz.eris@deu.edu.tr \\ Orcid No: 0000-0002-0652-3975 \\ Ömür Neczan TIMMURCANDAY ÖZMEN, Dokuz Eylül Üniversitesi, Türkiye, omur.ozmen@deu.edu.tr \\ Orcid No: 0000-0002-3379-317X \\ Burcu YANAR BAYAM, Dokuz Eylül Üniversitesi, Türkiye, burcu.yanar.bayam@gmail.com \\ Orcid No: 0000-0002-0294-0974
}

\begin{abstract}
Öz: Klasik anlamda mavi-beyaz ayrımı ile ișletme yazınında yer alan yaka kavramı özellikle son dönemde farklı renklerle ifade edilmeye bașlanmıstır. $\mathrm{Bu}$ çalışmada, iş yaşamındaki farklılaşan çalışan nitelikleri ve bu nitelikleri tanımlayan yaka kavramının değişen içeriği ve renklerini betimlemek amacıyla işletme yazını temelinde bir bibliyometrik analiz gerçekleștirilmiștir. Tarama kriterleri doğrultusunda 32 adet makale elde edilmiş ve analize dahil edilmiştir. Yazın taraması ve analiz sonucunda, farklı renklerdeki yakaların aslında birbirleri ile geçişli olduğu ve mavi-beyaz yaka şeklindeki ayrımın yeterli olmadı̆̆ sonucuna varılmıştır.
\end{abstract}

Anahtar Sözcükler: İş Yaşamında Yakalar, Altın Yaka, Beyaz, Yaka, Gri Yaka, Mavi Yaka, Pembe Yaka, Yeşil Yaka JEL Siniflandirmasi: M10, M12, M54, M19, J24

Abstract: Collar term in business literature has been changing recently and started to be expressed with not only traditional white and blue but also many different colors. In this study, to define collars with the new colors depending on differentiated work force qualification, a bibliometric analysis basis on business literature was carried out. Regarding the screening criteria, 32 articles were chosen and analyzed during the study. As a result of the literature review and the analysis, it was found that different color collars are actually transitive with each other, and it was concluded that only bluewhite collar classification is not sufficient.

\section{Keywords: Collar in Workplace, Gold Collar, White Collar, Gray/Grey Collar, Blue Collar, Pink Collar, Green Collar} JEL Classification: M10, M12, M54, M19, J24

\section{Giriş}

Özellikle Birinci Sanayi Devrimi sonrasında oluşan işletme kavramı ve temel bileșenlerinden birisi olan insan unsurunun tanımlanması yönetim yazınında önemli bir yer tutmuştur. İnsan Kaynakları yönetimi açısından örgütlerde istihdam edilen çalışanların niteliklerine ilişkin tanımlama ve sınıflandırma yönetsel kolaylık sağlama ve sistematik yönetim için önemli bir unsur olmuştur. Bu bağlamda çalışanların pozisyon ve niteliklerine ilişkin oluşturan "yaka" kavramı hem kuramsal olarak hem de uygulamada kullanılmaya başlamıştır. İş yaşamında çalışanların yaka renkleri ve bu renklerin ne anlama geldiğine ilişkin tartışmanın başlangıcı öncelikle "iş̧̧̧i sınıfı nedir?” sorusuna yanıt ile başlamaktadır. Karl Marx, Ekonomik Sınıf Modeli’nde *proleterya olarak tanımlanan işçi sınıfını; emeğinden başka bir üretim aracına sahip olmayan ve hayatını sürdürebilmek adına emeğini satan kişi/kişiler olarak ifade etmiştir. İşçi sınıfının tarih sahnesine çıkması ile birlikte işçi sınıfının örgütlü veya örgütsüz gücünden yararlanmak isteyen akımları da beraberinde getirmiştir. Bu noktada Marksizim işçi sınıfına tarihsel bir misyon yükleme görevini üstlenmiştir (Koç, 2013:46). Aslında Marksizim iktisat kuramından öte bir olgudur. Marksizmin özünde, sömürgeye dayalı ve insani potansiyelin tam gelişimini sınırlayan her toplumun reddi yatmaktadır (Lebowitz, 2006:1). Isşte tam da bu noktada sınıf kavramı gerek Marksizm içi tartışmaların gerekse Marksizme dönük eleştirilerin odak noktasını oluşturmaktadır.

Geçen yüzyılda özellikle de 1950’lerden sonra kapitalist toplumda yaşanan radikal dönüşümlerin daha önce var olan ve tanımlanan işçi sınıfını değişime uğrattığını, ideoloji ve siyaseti sınıf ilişkilerinden bağımsızlaştırdığını düşünenler (örn: Aron, 1950; Bell, 1973; Gorz, 1973; Giddens, 1980 vb.), daha öteye gidip, Marksizmin, sinıf ve sınıf mücadelesi kavramıyla birlikte çoktan tarihe karıştığını öne sürmüşlerdir. İş yaşamındaki "yaka" dolayısı ile "sınıf” kavramı, toplumsal alanda da benzer bir yapılanmayı beraberinde getirmiştir. Bu anlamda Weber (2003) de toplumsal sınıf kavramını kişilerin sahip oldukları çeşitli olanaklar açısından nitelemektedir. Toplum içindeki bu sınıfsal ayrım iş

\footnotetext{
1 Bu çalışma, aynı başlıkla 27. Ulusal Yönetim ve Organizasyon Kongresi’nde sözlü bildiri olarak sunulmuş olup kongre kitabında özet olarak yayınlanmıştır.
} Makale Gecmiși / Article History 
Eriş, E., D., Özmen, Ö., N., T., Bayam, B., Y. / Journal of Yasar University, 2020, 15/58, 259-269

yaşamında da benzer bir yansıma ile kendini göstermiş olup toplum içindeki işçi ve memur gibi ayrımlar kullanılmaktadır. Dolayısı ile iş yaşamı ve toplumsal yaşam karşılıklı olarak birbirlerini etkilemiş̧lerdir.

Toplumsal sınıf ve iş yaşamındaki sınıf ayrımına ilişkin bu tartışmalar devam ederken sanayileşme ile birlikte söz edilmeye başlayan ve mavi-beyaz yakalı olarak sınıflandırılan çalışanlar özellikle 1950'lerin sonunda ve 1960'ların başında Üçüncü Sanayi Devrimi yani bilgisayar ve bilgisayarlı sistemlerin devreye girmesi ile birlikte farklı grup dinamikleri altında renk değiştirmeye başlamıştır.

Günümüzün değişen, farklılaşan ve genişleyen ekonomik pazarları, hızla büyüyen hizmet sektörü ve zaman içeresinde bilgi iletişim teknolojilerinde yaşanan hızlı gelişim, mavi ve beyaz yakalı çalışan grupları dışında altın, gri, pembe ve yeşil olmak üzere yeni renk yakaların da ortaya çıkmasının en büyük nedenleridir. Bu alternatif/yeni yaka renkleri, mavi ve beyaz yaka çalışanların temel özelliklerinden ayrışarak örgüt içinde ortaya çıkan yeni işler ve bu işler için gerekli yetkinlikler açısından ele alınmaktadır. Alternatif yakaların insan kaynakları yönetimi uygulamaları açısından da farklılaşma yarattığı gözlemlenirken bu yakaların ne türde özelliklere sahip oldukları ve nasıl yönetilmeleri gerektiği de yeni bir tartışma konusu olarak görülmektedir.

$\mathrm{Bu}$ çalışmada, iş yaşamındaki farklılaşan çalışan nitelikleri ve bu nitelikleri tanımlayan yaka kavramının değişen içeriği ve renklerini betimlemek amaçlanmıştır. $\mathrm{Bu}$ amaca yönelik olarak da işletme yazını baz alınarak farklı disiplinlerdeki kullanımlar da dikkate alınarak bir bibliyometrik analiz gerçekleştirilmiştir.

\section{Kavramsal Çerçeve}

Özellikle işletme ve yönetim yazınında kullanılan ancak son dönemde farklı disiplinlerdeki yazında da karşılaşılan yaka kavramı ve renkleri tarihsel açıdan bakıldığında özellikle Birinci Sanayi Devrimi ile gündeme gelmiştir. Sanayi Devriminin beraberinde gelen büyük ölçekli işletmeler daha çok sayıda çalışanın istihdam edilmesine neden olmuştur. $\mathrm{Bu}$ dönemde sanayi sektörünün en kalabalık sınıfı olan mavi yakalı çalışanlar kol/kas gücünü kullanan ve özellikle ABD'de sendikaların ağır kütlesini oluşturan çalışanlar olarak ifade edilmiştir. Birinci ve İkinci Sanayi Devrimi ile birlikte ortaya çıkan "mavi yakalılar" iş yaparken kas gücünü kullanan genel olarak üretim sektöründe çalışan, bu nedenle de az kir, leke, ter gösteren mavi iş kıyafeti (tulum) giyen, saatlik ücret alan çalışan grubu olarak sınıflandırılmıştır. 1900’larda gelişmiş uluslarda imalat sanayinde mavi yaka olarak ortaya çıkan sınıfı Peter Drucker "tarihte hiçbir sınıf mavi yaka kadar hızlı yükselmemiş ve hiçbir sınıf bu kadar hızlı düşmemiştir” şeklinde ifade etmiştir (Taylor, 1995).

Tarihsel süreçte esas olarak yönetilen taraf oldukları için işletmeciliğin temel kaygısı verimlilikten hareketle iş yapan taraf olarak öncelikle mavi yaka ele alınmış, işletmecilikteki dönüşümle beraber sonraki çalışmalarda beyaz yakaya olan ilgi artmıştır. Doğrudan "Beyaz yakalı çalışanlar kimdir?" sorusunun sorularak cevap arandığı (Jenkins ve Sherman,1979:12-22; Bain ve Price, 1972) yazında İkinci Dünya Savaşı'ndan bu yana, beyaz yakalı ya da profesyonel olmayan endüstriyel çalışanlar kategorisi sosyal bilimlere nüfuz etmiştir. Beyaz yaka çalışanlar; genellikle büro çalışanları veya yönetici olarak anılan maaşlı profesyonellerdir. Adının genellikle mavi yakalılarda olduğu gibi giyim tarzından esinlenilerek profesyonellerin giydiği beyaz formalı gömleklerin renginden kaynaklandığı belirtilmektedir.

ABD’de yaşanan Büyük Buhran sonrasında 1930'lara gelindiğinde, sosyal yapı içindeki en büyük problemin beyaz yaka çalışanlar olduğuna dair yazılar yazında ve haberlerde yer almaya başlamıştır. Tatmin edici bir tanıma ulaşılamayan bu grup çalışanların cinsiyet, etnik köken ve gelir düzeyi itibari ile farklılık göstermesi bu sorunu ortaya çıkarmıştır. Yapılan araştırmalarda o dönemki beyaz yaka çalışanların \%60 oranında erkek ve \%90 oranında beyaz olduğu ifade edilmektedir (Edwards, 1934;501-503). 1930'ların iş hayatındaki büyük bir tartışma konusu beyaz yakanın etnik kökeni üzerine olmuştur. Özellikle siyahi çalışanların iş hayatındaki etkin rolü incelenmiştir (Lewis, 1939).

1940’lı yıllar geleneksel beyaz yaka çalışanlardaki değişimin daha güçlü hissedildiği bir dönem olarak tartışılmaya başlanmıştır. Özellikle teknolojik aletlerin gelişsimi ile ofis işlerindeki değişimin etkisi incelenmiştir (Fitzpatrick, 1948). O dönemde yapılmış görev tanımları incelendiğinde yönetsel pozisyonlardaki (örn: genel müdür, yönetici) yönetsel işlerin dışında (örn: profesyonel çalışanlar) yaratıcı işlerin de beyaz yakanın görevi olduğuna değinilmiştir (Wages...Hours, 1949). Diğer yandan maaşlı çalışanların değişimine ilişkin de yapılan incelemelerden birinde (Burns, 1954), 1890-1928 ve 1928-1952 dönemleri iki grup halinde incelenmiş ve özellikle eğitim sisteminin gelişmesi ile beyaz yaka işgücünün de önemli bir artış gösterdiği, gelişen teknoloji ile bu hızın daha da artacağı sonucuna varılmıştır.

1950’li yıllarla birlikte hizmet sektörünün gelişmesiyle beyaz yakalı çalışanların sayısında büyük artış olmuş ve 1956 yılına gelindiğinde ilk defa beyaz yakalılar endüstri uygarlığı içinde mavi yakalıların sayısını geçmiştir (Aktan ve Tunç, 1998). 1950'lerde beyaz yaka ile ilgili vurgulanan bir durum; tanımlamanın ve işin içeriği ile ilgili çeşitlenmenin ötesinde özellikle gelir düzeyi temelinde bir ayrım yapılmaya çalışılmasıdır (Flexner ve Ericson, 1956). Gelir odaklı bu yaklaşım aslında beyaz yakanın artan maddi beklentilerini göstermektedir. İlk defa 1939 yılında sosyolog Edwin Sutherland tarafindan gündeme getirilen beyaz yaka suçlar, mesleğinde itibarlı olan ve yüksek sosyal bir konuma sahip kişiler tarafından işlenen ve genellikle de maddi içerikli olan suçları ifade etmektedir (Sutherland, 1940). Öte yandan cazibesi artan beyaz yaka 1950 sonrasında hızlı yükselişini sürdürmüş, mavi yakadan beyaz yakaya geçiş oranı geleneksel özelliğe sahip beyaz yaka çalışanlardan daha hızlı olmuştur. Üstelik mavi yakadan beyaz yakaya geçiş üretim sektörünün dışında ağırlıklı olarak finans, ticaret ve hizmet sektörüne doğru gerçekleşmiştir (Barry, 1961). Bundaki bir etken de beyaz yaka çalışanların çalışma ortamlarının daha hijyenik ve güvenli olması da olabilir. Çalışanların yaptıkları işler nedeniyle maruz kaldıkları hastalıkları inceleyen çalışmalarda mavi yakanın beyaz yaka çalışanlara göre daha yüksek oranda hastalığa maruz kaldığı ve hastalık içeriklerinin de farklılık gösterdiği ifade edilmektedir (Goldstein ve Orris, 1964). İstihdam maliyetlerini yükselten beyaz yakanın işletmeye olan maliyetinin de kontrolü 1960'lardan itibaren öne çıkan bir konu 
olmaktadır. Çünkü ABD'de 1960'lara gelindiğinde beyaz yaka çalışanların toplam işgücü içindeki istihdam oranı 1950'lere göre iki katına çıkmıştır (Silberman, 1965). Britanya'da da savaş sonrası dönemde beyaz yakanın toplam işgücü içindeki oranının genişlediği ve daha derinleştiği görülmektedir (Elliot, 1977).

Bu dönemde her ne kadar örneğin sağlık alanında psikoterapide kendilerini ifade etmede güçlük yaşasalar da (Gould, 1968) hayat standartları açısından mavi yaka çalışanlar 1960'larda lüks tüketim malları açısından önemli bir alıcı konumuna gelmiştir. İş yaşamındaki motivasyonları ve kariyer planları incelendiğinde, Berger (1960)'in araştırmasında görüşme yapılan mavi yakalı çalışanların üçte ikisinin örneğin ustabaşı gibi bir üst pozisyona çıkmayı istemediğine ilişkin çarpıcı bir bulgu elde edilmiştir (Akt.Rachman ve Levine, 1966/67). Yine kırsaldan gelen ve şehirde yetişmiş mavi yakalı çalışanların sanayileşme sürecini kabul ve bağlılığı ile yapılan çalışmada önemli bir ayrım olmadığı mavi yakanın ortalama bir eğilim gösterdiği görülmektedir. 20. Yüzyılın ilk yarısı ABD ve diğer Avrupa ülkelerinde beyaz yakanın hızlı yükselişi (yaklaşık \%300 oranında bir büyüme oranı) ile ifade edilirken değişen ekonomik koşullar ve beyaz yaka snopluğu nedeniyle beyaz yakadan mavi yakaya geçiş (Punekar, 1966) de 1960'ların ilginç konularından birisidir. Beyaz ve mavi yaka arasında keskin bir ayrım olmadığına dair bir çalışmada Johnson ve Stern (1969:7), her beş beyaz yaka çalışandan bir tanesinin mavi yaka çalışma geçmişi olduğu görülmüştür. Beyaz yakanın artışında mavi yaka geçmişi olan çalışanların da oranı yükselmeye başlamıştır (Johnson ve Stern, 1970:472). İşe ilişkin değerler bakımından da çeşitlenen beyaz yaka çalışanların düşük statüye sahip olanları mavi yakalar ile benzerlik gösterirken üst düzeyin kendine has değerler sistemi olduğu Amerika ve Avrupa incelemelerinde görülmüştür (Pennings, 1970). Personel Journal'ın Mayıs 1968 sayısında bahsedildiği üzere, yönetimin belkemiği ve karar mekanizmasının merkezi olarak kendilerini tanımlayan beyaz yakalar, mavi yakalardan farklı olarak bilgi ve teknoloji kullanımı bakımından kendilerini üst konumda görmektedirler. İşe ilişkin farklılıklar açısından da beyaz erkeklerle yapılan çalışmada, başarma hissi beyaz yakada yüksek iken, mavi yakada yüksek maaş beklentisi görülmüştür (Weaver, 1975).

Toplumsal yaşam ve iş yaşamının geçişli yapısı nedeniyle özellikle 1950'lerde sadece iş yaşamında değil, toplumsal yapı düşünülerek öncelikli olarak sosyolojik açıdan ABD'de başlayan mavi ve beyaz yaka çalışan incelemeleri, 1970'lerle birlikte işletmecilik alanında (örn: Altimus ve Tersine, 1973; Srivastava ve Sinha, 1975; Hulme ve Bevan, 1975) İsveç (örn: Haanes-Olsen, 1972'den akt. Aldrich, 1982), Japonya (örn: Cook, 1972) ve Hindistan (örn: Muthuchidambaram, 1972) gibi farklı kıta ve ülkelerde de ele alınmaya başlanmıştır. Başta cinsiyetçi bir ayrım olmadan sadece erkek egemen bakış açısıyla incelenen mavi yakalılar Deaux ve Ulmann (1983) tarafından kadın işgücüne özgü bir bakış açısı ile de ele alınmıştır. Farklılıkların/çeşitliliklerin yönetimi bakış açısı ile cinsiyet bazlı ele alınmaya başlanmış olup daha sonra örneğin mavi yakalı çalışanlarda engellilik ve emeklilik durumu gibi farklı konularındaki çalışmalarla devam etmiştir (David ve Bigaouette 1989). Hatta bazı çalışmalarda cinsiyetle birlikte cinsel yönelim ve örgüt içindeki güç konularına da odaklanılmıştır (Williams, 1988).

1960'lı ve 1970'li y1llarda yapılan çalışmalar daha çok işçi hareketleri ve onların kurduğu örgütler üzerine yoğunlaşmaya başlamıştır (Çetinkaya ve Alkan, 2015:6). Özellikle de 1970'li yıllara gelindiğinde kapitalizmin altın çağının sona erişi ve yaşanan bunalımlar 1970'lerin ikinci yarısından itibaren işçi sınıfının olası durumunu ve sendikacılık hareketlerini doğrudan etkisi altına almıştır.

1980'lerde ise küreselleşme ve geleneksel iş yapılarındaki değişimler ve beraberinde beyaz yakanın verimliliğinin de sorgulanması ile dikkat çekmektedir (Berglind ve Scales, 1987). Bu dönemde bilgisayar teknolojisinin gelişmesi ile iş türlerinde ve içeriklerinde hızlı değişimin başlaması (örn. e-posta kullanımı) (Wickham, 1987) ve bu nedenle iş kayıpları, beyaz yakanın kurumsal işletmelerden ayrılıp girişimciliğe yönelmesi ve evden çalışmaya başlamaları (Kraut ve Grambsch, 1987) dikkat çekmektedir. Strese dayalı değişimler ve incelemelerin olduğu (Frankenhaeuser vd. 1989). 80’ler aynı zamanda beyaz yaka suçların da yoğunlukla incelendiği yıllar olmuştur. Sonrasında ise Amerika iş dünyasında ciddi bir değişim olduğu ifade edilmektedir. Örneğin daha önce Fortune 500 listesinde yer alan birçok firmanın listeden çıktığı, el değiştirdiği, bölündüğü ve bu arada beyaz yaka çalışanların (özellikle de üst yönetimin) işsiz kaldığı yönünde bir yeniden yapılanmanın dikkat çekici olduğu görülmüştür (Walker, 1996).

1990'lara gelindiğinde, mavi yakanın ABD toplam işgücü içinde \%30’luk bir ağırlığının olduğu (Malkinson vd., 1997) otomasyonun, bilgi ve iletişim teknolojilerinin işletmelerde daha yoğun kullanılması ve işin içeriğinde yaşanan değişimler nedeniyle mavi yaka çalışanların bilgi işçisi rolüne de geçiş sağladıkları görülmektedir (Cusimano, 1995). Gelişen bilişim teknolojileri ile beyaz yakalı çalışanların iş kaybı daha sık görülmeye başlanmıştır. Bunun temel iki nedeni; beyaz yaka çalışanların teknoloji kullanımını uzmanlara bırakmayı tercih etmesi, daha önceden rutin işlerde kullanılmaya başlanan bu teknolojileri öğrenmeye ve kullanmaya değer görmemesidir (Davis, 1991). Teknolojinin gelişimi ile beyaz yaka çalışanların verimliliği yeniden sorgulanmaya başlamıştır. Zaman yönetimi gibi başlıklarda çalışanların daha etkin çalışması inceleme konusu olmuştur (Singhvi, 1993). Diğer yandan örneğin karar verme gibi temel bir beyaz yakalı çalışanın görevinin bilgisayarlar tarafından yapılması durumu sorgusunda ise gelişen bilgisayarların daha yüksek oranda doğru karar verdiği görülmüştür (Ashton vd., 1994). Teknolojinin hem beyaz hem de mavi yaka açısından yeniden tanımlamaya yol açtığı Gallie (1996) tarafından ifade edilmiştir. Bu arada sadece ABD'de değil, dünya ekonomisi içinde önemli yer tutmaya başlayan örneğin Japonya gibi ülkelerde de (Hori, 1993) beyaz yakaya ilişkin sorgulama 90'ların konusu olmuştur.

2000'li y1llar 90'larda yaşanan resesyon, yeni ekonomi gibi faktörler nedeniyle hem örgüt biçimlerinde hem de örgüt içindeki görevlerde yeniden yapılanma zamanı olarak ele alınırken (Seppala, 2004), mavi yakaya ilişkin olarak motivasyon, iş yerinde stres, performans (Takala vd., 2006) gibi örgütsel davranış ve insan kaynakları konularının inceleme konusu olduğu görülmektedir. Bu dönemde mavi yaka çalışanların özellikle strese bağlı yaşanan sağlık sorunları 
açısından da incelendiği (örn: kalp hastalıkları Nakamura vd., 2000; alkol bağımlılı̆̆1 Bamberger vd., 2006) dikkat çekmektedir.

Dünyada işçi sınıfı yeni bir boyut kazanırken, Türkiye'de de tarihsel boyutta yazında sadece “büyük adamlar”ın oynadığı temel roller üzerinde durulmuştur. Örneğin devlet adamları, kahramanlar, komutanlar, liderler gibi ana karakterlerin merkezinde bir tarihsel kurgu yapılmıştır. Bu nedenle göreli olarak dünyadaki çalışmaların gerisinde kalınmıştır. Osmanlı İmparatorluğu’nda ve Türkiye’de işçi sınıfı tarihi üzerine yapılan çalışmaların çoğu, sendikalar, örgütlü hareketler, siyasi mücadeleler, işçi liderlerinin ayaklanmaları ve grevleri üzerinedir. Yazında benzer şekilde işçi sınıfı tarihinin farklı yönlerinin örneğin toplumsal yaşam, farklılıkların/çeşitliliklerin yönetimi kapsamında yer alan cinsiyet, etnik köken, kültür, din, kimlikler vb. konuların ele alınması 1960'lardan sonra olmuştur. Aslında modern Türkiye tarihinde bir işçi tarihinden bahsedilemeyeceği görüşünün ortak paydası kullandıkları tanım ve tespitlerin yanı sıra tarihsel süreçte yaşanan gelişmeler olmuştur. Literatürün tamamında uzunca bir dönem işçi sınıfını sanayi devriminin bir sonucu olarak ortaya çıkan fabrika tipi sanayi tesislerinde çalışan ücretli, erkek, mavi yakalı kol emekçileri olarak ele aldığı görülmüştür. Ancak 1990’lı ve 2000'li yıllardan sonra politik, toplumsal, iktisadi ve kültürel bir dönüşümü deneyimleyen yeni bir kuşak ile birlikte tarih çalışmalarına yönelinip "işçi sınıfı" tam anlamı ile gündeme gelebilmiştir (Çetinkaya ve Alkan, 2015:8-10 ve 28).

\section{Araştırma}

\subsection{Araştırmanın Amacı}

İş yaşamında aktif olarak yer alan çalışanları sınıflandırma yolu olarak kullanılan "yaka” kavramının Birinci Endüstri Devrimi sonrasında yaşanan gelişmelere bağlı olarak ortaya çıktığı genel kabul gören bir görüştür. Başlangıçta mavi ve beyaz olmak üzere iki sınıfta ele alınan işletme personeli, tarihsel süreçte yaşanan endüstri devrimleri ve çeşitlenen iş alanları ile birlikte değişime uğramış ve çeşitlenmiştir. Bu noktada aslında yazında var olan fakat ön plana çıkmayan ve yaygın olarak da sadece mavi ve beyaz olarak sınıflandırılan işletme personeli altın, gri, pembe ve yeşil yakalı şeklinde ifade edilmeye başlanmıştır. Özellikle yeni nesil çalışan gruplarının iş yaşamında var olmaya başlaması ile yapılacak olan araştırmalarda örneklemin doğru seçimi ve çalışanların niteliklerini ortaya koyabilmek açısından yakaların yazında net biçimde tanımlanması önem arz etmektedir.

$\mathrm{Bu}$ gereklilikten hareketle çalışmanın amacı, yazında kavramsal olarak arka planda kalan ve yeni kullanılmaya başlanan yakaların (altın, gri, pembe ve yeşil) tanımlanması ve kavramsal kargaşayı ortadan kaldırabilmeye yönelik ışık tutabilmektir.

\subsection{Araştırmanın Tasarımı}

Yazında iş yaşamında yer alan alternatif yakalara yönelik yazındaki kavramsal kargaşanın yarattığı sorunsalın incelenmesine ilişkin yapılandırılan bu çalışma, betimsel olup nitel bir araştırma olarak tasarlanmıştır. Araştırmada ikincil verilerle analiz gerçekleştirilmiş olup bibliyometrik analiz tekniği kullanılmıştır.

Çalışmanın ana kütlesini Sosyal ve Beşeri Bilimler alanında "yönetim” ve "insan kaynakları” konulu çalışmalar oluşturmaktadır. Amaçlı (benzeşik) örneklem kullanılarak amaca yönelik olarak Web of Science ve Ulakbim'de Türkçe ve İngilizce dillerinde yayımlanmış olan akademik dergiler taranmıştır. Tarama yeri makale başlı̆̆ olup, Türkçe olarak "altın yaka", "gri yaka”, “pembe yaka”, “yeşil yaka” ve İngilizce olarak da "gold collar”, "gray/grey collar”, "pink collar” ve "green collar" anahtar kelimeleri kullanılmıştır. Tarama sonucunda 32 adet makale amaca uygun olarak bulunmuş ve analize konu olmuştur, içerik ve medtod yönlü sınıflama yapılmıştır.

\subsection{Bulgular}

Araştırma tasarımında bahsedilen ölçütler doğrultusunda yapılan tarama sonucunda ulusal yazında dört anahtar kelime grubu ile (altın yaka, gri yaka, pembe yaka, yeşil yaka) üç farklı dergide üç yayına ulaşılmıştır. Uluslararası yazında ise yine dört anahtar kelime grubu ile (gold collar, gray/grey collar, green collar, pink collar) 29 farklı dergide toplam 29 yayın elde edilmiştir. Toplamda ulaşılan 32 makale (Tablo 1) kavramsal tanımlama, yıl, ülke, çalışma alanları, işin gereği, eğitim düzeyi ve ücret düzeyi ölçütleri açısından sınıflandırılmıştır. 
Eriş, E., D., Özmen, Ö., N., T., Bayam, B., Y. / Journal of Yasar University, 2020, 15/58, 259-269

Tablo 1. Ulusal ve Uluslararası Yazındaki Makaleler

\begin{tabular}{|c|c|c|c|c|}
\hline \multirow[b]{2}{*}{ Renkler } & \multicolumn{2}{|c|}{ Ulusal Yazın } & \multicolumn{2}{|l|}{ Uluslararası Yazın } \\
\hline & Yazarlar & $\begin{array}{l}\text { Yayın } \\
\text { Sayısı }\end{array}$ & Yazarlar & $\begin{array}{l}\text { Yayın } \\
\text { Sayısı }\end{array}$ \\
\hline Altın-Gold & $\begin{array}{l}\text { Yüksel, (2010) } \\
\text { Şener, (2016) }\end{array}$ & 2 & $\begin{array}{l}\text { Tom, (1986) } \\
\text { Sadler, (1994) } \\
\text { Landrum, (1997) } \\
\text { Bunk (1999) } \\
\text { Roe, (2001) } \\
\text { Holland vd., (2002) } \\
\text { Roongrerngsuke ve Liefooghe, (2013) } \\
\text { Kaščák ve Pupala, (2013) }\end{array}$ & 8 \\
\hline $\begin{array}{l}\text { Gri } \\
\text { Grey/Gray }\end{array}$ & - & - & $\begin{array}{l}\text { Kudera, (1983) } \\
\text { Allen, (2005) } \\
\text { Hutchings vd., (2009) } \\
\text { Ling vd. (2018) }\end{array}$ & 4 \\
\hline Pembe-Pink & - & - & $\begin{array}{l}\text { McLaughlin, (1983) } \\
\text { Hunt, (1993) } \\
\text { Rung, (1997) } \\
\text { Kouzmin vd., (1999) } \\
\text { Lane, (2000) } \\
\text { Liben vd., (2001) } \\
\text { Lips-Wiersma vd., (2016) } \\
\text { Kalokerinos vd., (2017) }\end{array}$ & 8 \\
\hline Yeşil-Green & Ercoşkun, (2010) & 1 & $\begin{array}{l}\text { Pinderhughes, (2006) } \\
\text { Pearce ve Stilwell, (2008) } \\
\text { Marszalek, (2008) } \\
\text { Carr, (2009) } \\
\text { Hazell, (2009) } \\
\text { Harvey vd. (2010) } \\
\text { Shear, (2012) } \\
\text { Pettinger, (2017) } \\
\text { Pettinger vd. (2017) }\end{array}$ & 9 \\
\hline
\end{tabular}

Tablo -1'de görüldüğü üzere uluslararası yazında farklı çalışmalara konu olan yakaların özellikle son dönemlerde çoklu disiplinler ile birlikte ele alındığı bazı kavramların da aynı anlamda (Örn: Altın yakalı ve bilgi işçisi) kullanıldı̆̆ görülmektedir. Ulusal yazında ise çalışma sayısı oldukça azdır ve 2010 yılından sonra alternatif yaka renklerinin kullanımına rastlanmaktadır.

\subsection{Alternatif Yaka Renkleri}

Tarama sonucunda elde edilen makalelerin ağırlıklı olarak kavramsal ve normative olduğu, 2000 yılından sonra alternatif yakalar ile ilgili çalışmaların arttığı, yayınların genellikle Kuzey Amerika'da yapıldığı ve araştırma alanını da hem imalat hem de hizmet işletmelerinin oluşturduğu görülmektedir.

Yazındaki çalışmalardan hareketle alternatif yakalara ilişkin özet sınıflama Tablo 2'deki gibidir. 
Eriş, E., D., Özmen, Ö., N., T., Bayam, B., Y. / Journal of Yasar University, 2020, 15/58, 259-269

Tablo 2. Yakaların Sinıflandirılması

\begin{tabular}{|c|c|c|c|c|c|}
\hline $\begin{array}{c}\text { Yaka } \\
\text { Renkleri }\end{array}$ & Ülke & Çalışma Alanları & İşin Gereği & $\begin{array}{c}\text { Eğitim } \\
\text { Düzeyi }\end{array}$ & $\begin{array}{c}\text { Ücret } \\
\text { Düzeyi }\end{array}$ \\
\hline Mavi & $A B D$ & Üretim Bandı (işçi) & Kas Gücü & Düşük & Düşük \\
\hline Beyaz & $A B D$ & Kurumsal Alanlar (memur) & Zihin Gücü & Yüksek & Yüksek \\
\hline Altın & ABD & Üst Yönetim & Zihin Gücü & Yüksek & Yüksek \\
\hline Gri & ABD \& Çin & Üretim Bandı ve Kurumsal Alan & Kas ve Zihin Gücü & Orta & Orta \\
\hline Pembe & ABD & Kurumsal Alan & Zihin Gücü & Orta & Orta \\
\hline Yeşil & ABD & Tüm Alanlar & Zihin Gücü & Yüksek & Yüksek \\
\hline
\end{tabular}

Yaka kavramının yönetim ve işletme bilimi ile birlikte çok disiplinli bir olgu olduğu, yönetim, sağlık ve mühendislik alanlarında da çalışmaların yapıldığı görülmektedir. Ayrıca yakaların birbirleri ile ve başka kavramlarla da geçişli olduğu dikkat çekmektedir. Özellikle altın yaka kavramı "bilgi işçisi” eş anlamlı olarak da kullanılmaktadır.

Yapılan çalışmalarda hem imalat hem de hizmet sektörünün çalışanlarına yer verildiği özellikle son 10 yılda daha çok hizmet sektörü yönlü incelemlerin olduğu görülmektedir.

Bu yakalara ilişkin sınıflamanın Batı, özellikle de Kuzey Amerika kökenli olması ulusal yazında daha fazla kavramsal ve görgül çalışmaya yer verilmesi gerekliliğini de göstermektedir.

\subsubsection{Altın Yaka}

Alternatif yakaların tanımlanması ile ilgili olarak tartışılan yaka renklerinden birisi altın yaka çalışanlardır. Bu çalışanlar, teknolojik ilerlemeler, klasik üretim anlayışının yerini modern üretim anlayışına bırakması, sanayi toplumundan hizmetler sektörüne geçiş, küreselleşme gibi gelişmelerin yeni kavramları da beraberinde getirmesi ile ortaya çıkan bir çalışan grubudur. Bilgi toplumunun oluşumu, mavi ve beyaz yaka çalışanların ihtiyaçları karşılama konusunda yetersiz kalmaları ve bilgi işinde bedeni çalışmanın yerini zihni çalışmanın, mal üretimin yerini ise hizmet üretiminin alması ile yazında bilgi işçisi ilk defa 1959 yılında Peter Drucker ve tarafından tanımlanmış ve altın yaka kavramı da yazında yerini almaya başlamıştır. Genellikle hizmet sektörü içinde ele alınan bilgi işi, eğitimden sağlığa, mühendislikten iktisada, hukuktan mimariye pek çok meslek dalıyla ilgili geniş bir yelpazeye sahiptir. Bilgi işçileri ise çeşitli düzeylerde bilgi işi ile uğraşan, bilgiyi üreten, toplayan, depolayan, analiz eden ve eşgüdümleyen çalışanları ifade etmektedir (Ersel, 2003; Koçak ve Uygun, 2011).

\subsubsection{Gri Yaka}

Gri yakalı çalışanlar ile ilgili olarak yazında iki temel görüş hâkimdir. Birincisi mavi yakalılardan yüksek, beyaz yakalılardan düşük vasıflara sahip olan, mavi ve beyaz yaka arasındaki iletişimi sağlayan, işin içinde yetişmiş, teknoloji kullanımı konusunda beyaz yakalılar kadar aktif olmayan fakat mavi yakalılardan daha iyi düzeyde iş yapabilen şef, ustabaşı, vardiya amiri, postabaşı gibi unvanlara sahip çalışan grubudur. İkinci görüş ise daha çok işgücü içinde yaşlanan bir nüfusu tarif etmek için kullanılmaktadır. Batı'da yaygın olarak kullanılmasına rağmen, Çin'de beyaz ya da mavi yakalı işçilerden farklı olarak ara elemanlar, teknisyenler sıklıkla bu yaka rengi ile anılmaktadır (Hutchings vd.,2009). Wright (2002), ise gri yakalı çalışanları "yetenekli teknisyenler", iş tanımlarına göre bazı beyaz ve bazı mavi yakalıların görevlerini birleştiren çalışanlar" olarak tanımlamıştır. Gri yaka, beyaz veya mavi olarak sınıflandırılmayan istihdam edilenlerin dengelerini belirtir. Çoğu zaman bu işçiler emeklilik dışında çalışanlardır. Esas olarak yarı zamanlı çalışan veya istihdam altındaki beyaz yakalılar olarak ifade edilmektedir.

\subsubsection{Pembe Yaka}

Pembe yakalılar ile ilgili olarak yazında önemli birkaç detay göze çarpmaktadır. Özellikle savaş dönemlerinde erkeklerin savaşa katılmak üzere işlerinden ayrılmaları durumunda onların yapması gereken işlerin büyük bir çoğunluğunun kadın çalışanlar tarafından yerine getirilmesi "pembe yaka" kavramının gündeme gelmesine neden olmuştur. Ayrıca hizmet sektörünün de 1950'li ve 1960'lı yıllarda genişlemesi sonucu ağırlıklı olarak büro işlerinin yer almaya başlaması ile daha düşük ücretlerle büro ve idari destek pozisyonlarında kadın çalışanlar istihdam edilmiştir. Ayrıca bu noktada kadın çalışanların yaptıkları büro işlerinin (örneğin, sekreterlik gibi pozisyonlarda çalışan bazı erkeklerin hoşnutsuzluk duydukları ve erkek kimlikleri ile ilgili birtakım sıkıntılar yaşadıkları) erkek çalışanlarca da yapılmaya başlanmış olması 
Eriş, E., D., Özmen, Ö., N., T., Bayam, B., Y. / Journal of Yasar University, 2020, 15/58, 259-269

“pembe yakalı” erkek çalışanların da varlığını gündeme getirmiştir (Williams, 1993). Başlangıçta önemsiz çalışanlar gibi görülüp, basit işler verilen pembe yakalı çalışanların yaptıkları işler ile kendilerini göstererek sonrasında özellikle de kamu sektöründe -yönetsel pozisyonlar da dâhil olmak üzere- zaman içinde belirgin bir rol üstlendikleri görülmüştür (Mclaughlin, 1983). İstihdam edilen pembe yakalı çalışanlar ağırlıklı olarak; eğitim (okul öncesi, ilk ve orta öğretim), sağlık (hemşireler, güzellik uzmanları vb.), havacılık (yer ve hava hostesi) sektörlerinde öne çıkarken kütüphane ve dokümantasyon personeli, ev işlerinde yardımcı personel, ön büro hizmetleri ve sekreter dendiğinde de yine pembe yakalı çalışanlar akla gelmektedir.

Özellikle bilişim teknolojilerinin gelişmesi birçok sektörde insangücünü elimine etmiş ve bu kişiler (özellikle de kadınlar) hizmet sektörüne yönelmiştir. Bu işler arasında evde hasta/yaşlı bakıcılığı, çocuk bakıcılığı öne çıkmaktadır ve bu çalışanlara da pembe yakalı denmektedir (Kouzmin vd., 1999). Günümüzde ise girişimci kadınlar için pembe yakalı ifadesi kullanılmaya başlanmış ve Türkiye'de Türkiye Genç İşadamları Konfederasyonu (TÜGİK) ile Küçük ve Orta Ölçekli İşletmeleri Geliştirme ve Destekleme İdaresi Başkanlığı (KOSGEB) tarafından "Pembe Yaka Projesi”" hazırlanmıştır.

\subsubsection{Yeșil Yaka}

Son dönemde yaşanan teknolojik gelişmelerle tüm dünyada çevre, enerji verimliliği ve yenilenebilir enerji yatırımlarının istihdam üzerindeki etkisinin giderek artması ile birlikte yeşil işler, yeşil meslekler olarak tanımlanan "yeşil yakalı" çalışan grubunun ortaya çıkmasına neden olmuştur. Birleşmiş Milletler Çevre Programı'nda yer alan tanıma göre "yeşil işler” ya da bir başka deyişle yeşil yakalı meslekler (yenilenebilir enerji danışmanlığı, yenilenebilir enerji mühendisliği, rüzgar enerjisi uzmanlığ1, rüzgar enerjisi teknikerliği, karbon satış uzmanlığ 1 , çevre ve enerji hukuku uzmanlığı, organik tarım mühendisliği, ekolojik turizm danışmanlığı, 1S1 yalıtım uzmanlığı, çevre mühendisliği, ekolojik bina tasarımcılı̆̆ı, atık su uzmanlığı gibi) imalat, tarım, hizmet ve Ar-Ge sektörlerinde insanlığın karşı karşıya olduğu çevresel tehditleri gidermeyi amaçlayan işler ve meslekler olarak ifade edilmektedir (Hemlock, 2007; UNEP, 2008; Erdal, 2012).

$\mathrm{Bu}$ durum, gelecekte öne çıkacak yeni mesleklerin yeşil yakalı çalışanlardan oluşacağını göstermektedir. Ayrıca dünyada var olan yeşil dalga hareketi ve çevreye yapılan yatırım, yeşil yakalıları sadece bir meslek ya da örgütte belirli işleri yapan çalışanlar olmanın dışında yeni pazarlar ve yeni işler, aynı zamanda basit teknolojiye dayalı Retro ürünler, yeşil teknolojik inovasyonlar ve yeni yeşil endüstrilerle de eşleştirmektedir (Shear, 2012).

\section{Sonuç ve Öneriler}

Uluslararası ve ulusal yazında çalışan sınıflandırılmaları ile ilgili tanım birliğinin olmaması, ağırlıklı olarak mavi ve beyaz yaka kavramlarının kullanılmasının tercih edilmesi ve daha gelecekçi bir yaklaşımla geleceğin mesleklerinin göz önüne alınmasının gerekliliği ile, yazında yakalara yönelik kavramlaştırma ve kullanımlarına ilişkin net bir tanımlama gereksinimini ortaya çıkarmıştır. Bu gereksinimden hareketle gerçekleştirilmiş olan çalışma, farklı disiplinlerde ele alınan ancak özellikle işletme ve yönetim açısından kullanılan ve tartışılan yaka renklerine açıklık sağlamaktadır.

Yazındaki geçmiş çalışmalar incelendiğinde "yaka" kavramının işçi sınıfı oluşumu ile gündeme geldiği ve öncelikli olarak sosyolojik açıdan ele alındığı sonrasında ise hukuksal süreçler dikkate alınarak hukuk açısından incelendiği görülmüştür. Işletme biliminde örgütsel davranış ve insan kaynakları açısından ele alınan yaka kavramının değişen örgütsel roller ve işin içeriği nedeniyle farklı renklerde tanımlanmaya başladığı görülmüştür.

Yayınlar incelendiğinde farklı renklerdeki yaka renklerinin aslında birbirinden keskin çizgilerle ayrılmadığı, çalışan nitelikleri ve iş olanakları açısından geçişli bir yapıya sahip olduğu görülmektedir. Kullanılan kavramlardaki geçişlilik (örn: altın yaka ve bilgi işçisi) zamanla çalışanların kendini geliştirerek farklı bir pozisyona geçerek yaka renginde değişikliğe gidebileceğini de göstermektedir. Bu bağlamda aslında "Alternatif olarak bahsedilen farklı yaka renkleri (örn: altın, gri, pembe, yeşil) gerçekten alternatif mi yoksa ayrı birer yapıyı mı ifade etmektedir?" ya da "Yapay zeka uygulamalarının gelişmesi ile birlikte insan istihdamı ve yaka renkleri tamamen mi ortadan kalkarak sadece demir yaka çalışanlar mı olacak?” sorusu araştırmada öne çıkan bir diğer önemli husustur. Bu sorulara ilişkin sorgulama bundan sonra yapılacak olan çalışmaların ana konusu olarak gündeme gelebilir.

Araştırmada dikkat çeken bir diğer nokta ise yeşil yakalıların özellikle aldıkları eğitimler ve uzmanlık alanları açısından değerlendirildiğinde fen bilimleri ve sağlık alanları ile ilgili (Örn: Journal of Occupational \& Environmental Medicine, American Journal of Industrial Medicine, Resource and Energy Economics, Research Journal of Recent Sciences) dergilerde ağırlıklı olarak yer almasıdır. Bu sonuç, genel yönetim ve insan kaynakları yönetimi açısından değerlendirilen yakaların çok disiplinli bir kavram olmasına ilişkin ipucu da vermektedir. Cinsiyet eşit(siz)liği bağlamında da pembe yaka çalışanlarda var olan cinsiyetçi yaklaşım yazında dikkat çekilmesi gereken bir konu olarak göze çarpmaktadır (Kalokerinos vd., 2017). Bu noktadan hareketle gelecek çalışmaların da salt yönetim ve insan kaynakları yönetimi açısından değil diğer disiplinler ile birlikte ele alınması gerektiği söylenebilir. Ancak tüm bunların ötesinde, yeni işler, yeni pozisyonlar ile ilgili çalışmalar yapılırken, cinsiyet faktörü de göz önünde tutularak yazında gelenekselleşen mavi-beyaz yaka sınıflaması dışında mutlaka alternatif yakalar da dikkate alınmalıdır.

Ulusalarası yapılan değerlendirmeden sonra ulusal açıdan bakıldığında ise Çetinkaya ve Alkan (2015) tarafından yapılan incelemede Türkiye'de işçi sınıfı ile ilgili yazının belirli bir seviyenin altında kalan kısmının özelliklede arşiv kaynaklarının yetersiz olduğu görülmüştür. Ancak hem uygulama hem de akademik çalışmalar açısından dikkat edilmesi gereken bir nokta ise Türkiye'de hukuksal olarak yapılan değerlendirmede, Yargıtay 9. Hukuk Dairesi iş mevzuatında beyaz-mavi yaka ayrımı olmadığı, örneğin çalışanlar arasında fazla çalışma, bayram ve genel tatil ücretleri bakımından 
Eriş, E., D., Özmen, Ö., N., T., Bayam, B., Y. / Journal of Yasar University, 2020, 15/58, 259-269

farklı oranların uygulanmasının İş Kanunu'nun 5. maddesine aykırı olduğuna dikkat çekilmektedir. Bu noktadan hareketle akademik çalışmalarda da örneklem olarak mavi-beyaz yaka ayrımının aslında yeterli olmadığı görülmektedir.

$\mathrm{Bu}$ çalışmanın, yakalar konusunda özellikle ulusal yazında yeterli sayıda çalışmanın olmaması, bununla birlikte var olan çalışmalarda tanım birliğinin ve sınıflandırmanın yeterli olmaması nedeniyle elde edilen bulgular ile ileri sürülen görüşler bundan sonraki araştırmalara ışık tutması beklenmektedir. 
Eriş, E., D., Özmen, Ö., N., T., Bayam, B., Y. / Journal of Yasar University, 2020, 15/58, 259-269

\section{KAYNAKÇA}

Aktan, C. ve Tunç. M. 1998. Bilgi Toplumu ve Türkiye. Yeni Türkiye Dergisi, Ocak-Şubat 1998:118-134.

Aldrich, J. 1982. The Earnings Replacement Rate of Old-Age Benefits in 12 Countries, 1969-80. Social Security Bulletin. November 1982. 45(11):3-11.

Allen, M.T. 2005. Grey-Collar Worker: Organisation Theory In Holocaust Studies. A Journal of Culture and History. 11(1):27-54.

Altimus J.R. ve Tersine, R.J. 1973. Chronological Age and Job Satisfaction: The Young Blue Collar Worker. Academy of Management Journal. 19(1): 53-66.

Aron, R. 1950. Social Structure and The Ruling Class, British Journal of Sociology. 1.

Ashton. A.H.; Ashton. R.H. and Davis. M.N. 1994. White-collar robotics. In: California Management Review. 37(1):83109.

Bain, G.S. and Price, R. 1972. Who Is A White Collar Employee, British Journal of Industrial Relations. 10(3):325-339.

Bamberger P.; Sonnenstuhl W. and Vashdi, D. 2006. Retirement, risky alcohol consumption and drinking problems among blue-collar workers. Journal of Occupational Health Psychology Issn: 1076-8998, Jan. 11(1):119-34.

Barry, C. 1961. White-Collar Employment: II-Characteristics. White Collar Employment; Trends, Structure and Characteristics. Monthly Labor Review (Pre-1986). 84(2):139-147.

Bell, D. 1973. The Coming of Post Industrial Society, New York: Basic Books.

Berglind, B.L. ve Scales, C.D. 1987. White-Collar Productivity: Seeing Through The Camouflage. Management Review (Jun. 87). 76(6): 41-46.

Bunk, S. 1999. How To Manage Knowledge and Gold Collar Workers. The Scientist Journal. 13(3):16-17.

Burns, R.K. 1954. The Comparative Economic Position of Manual and White-Collar Employees. The Journal of Business. White-Collar Unionism. (Oct., 1954) 27(4):257-267.

Carr, D. 2009. Green-Collar Jobs, Market Facing A Difficult Year. Ends Report. 434:38-41.

Cook. A. H. 1972. The blue-collar worker in Japan. In: Monthly Labor Review. 95(2):91-92.

Cusimano, J. M. 1995. Turning blue-coller workers into knowledge workers. Training and Development Journal. 49(8): 47-49.

Çetinkaya, Y.D. ve Alkan Ö. M. 2015. Tanzimattan Günümüze Türkiye İşçi Sınıfının Tarihi 1839-2014 Yeni Yaklaşımlar, Yeni Alanlar, Yeni Sorunlar. Tarih Vakfi Yurt Yayınları.

David, H. ve Bigaouette, M. 1989. Bigaouette Inaptitude au travail et prises de retraite chez les ouvriers d'une grande municipalité. Travail Humain. 52(2):131-146.

Davis, T. R. 1991. Information technology and white-collar productivity. Academy of Management Executive. 5(1):5567.

Deaux K. and Ullman. J. C. 1983. Women of Steel: Female Blue-Collar Workers In The Basic Steel Industry. New York: Praeger.

Edwards, A.M. 1934. The White Collar Workers. Monthly Labor Review. 5p. Publisher: Us Department of Labor. 38(3):501-505.

Elliott, R. F. 1977. The Growth of White-Collar Employment In Great Britain (1951-1971). British Journal of Industrial Relations. 15(1):39-44.

Ercoşkun, Ö.Y. 2010. Yeşil Yakalı Kavramı ve Türkiye'deki Yeşil Yakalılar. Çağdaş Yerel Yönetimler Dergisi. 19(3):2548.

Erdal, L. 2012. Türkiye'de Yenilenebilir Enerji Yatırımları ve İstihdam Yaratma Potansiyeli. Sosyal ve Beşeri Bilimler Dergisi. 4(1):171-181.

Ersel, B. 2003. Bilgi Çağında Çalışma Ilişkileri ve Beyin Göçü. İzmit: 2. Ulusal Bilgi, Ekonomi ve Yönetim Kongresi.

Fitzpatrick, S. 1948. The White Collar Worker and Wall Street. The American Catholic Sociological Review. (Jun., 1948). 9(2):98-107.

Flexner. J.A. and Ericson. A. 1956. White-Collar Employment and Income. Monthly. Labor Review. (April, 1956: Page:7)

Frankenhaeuser M.; Lundberg U; Fredrickson. M.; Melin. B.; Martti Tuomisto; Myrsten. A.; Hedman. M.; BergmanLosman B. ve Wallin. L. 1989. Stress on and off the job as related to sex and occupational status in white-collar workers In: Journal of Organizational Behavior. 10(4):321-346.

Gallie, D. 1996. New Technology and the Class Structure: The Blue Collar/White-Collar Divide Revisited. British Journal of Sociology. September 1996. 47(3):442-473.

Giddens, A. 1980. The Class Structure of Advanced Societies, London: Hutchinson.

Goldstein, D.H. ve Orris, L. 1964. Diseases of White Collar Workers. Public Health Reports Nov.1964. (1896-1970). 79(11):958-962.

Gorz, A. 1973. Socialism and Revolution. Garden City: Anchor Books.

Gould, R. E. 1968. Dr. Strangeclass or: How I stopped worrying about the theory and began treating the blue collar worker. Journal of Contemporary Psychotherapy. September. 15p. 1(1):49-63.

Harvey D.M., Bosco, S.M. ve Emanuele, G. 2010. The Impact of "Green-Collar Workers" On Organizations. Management Research Review. 33(5):499-511.

Hazell, S. 2009. Green Collar Revolution. Alternatives Journal; Waterloo. 35(6):8-11. 
Eriş, E., D., Özmen, Ö., N., T., Bayam, B., Y. / Journal of Yasar University, 2020, 15/58, 259-269

Hemlock, D. 2007. Green Revolution. Orlando Sentinel. Http://Innovations.Harvard.Edu Erişim Tarihi: 12.12.2018

Holland, P. J.; Hecker, R. ve Steen, J. 2002. Human Resource Strategies and Organizational Structure For Managing Gold Collar Workers. Journal of European Industrial Training. 26(2):72-80.

Hori, S. 1993. Fixing Japon's white-collar economy. A personel view. Harvard Business Review. 25(6):157-168.

Hulme, R. D. ve Bevan, R. V. 1975. Harvard Business Review, March 1975, 53:104-112.

Hunt, G. 1993. Sex Differences In A Pink-Collar Occupation. Relations Industrielles / Industrial Relations Journal. 48(3):441-460.

Hutchings K., Zhu C., Cooper B.K., Zhang Y. ve Shao, S. 2009. Perceptions of The Effectiveness of Training and Development of 'Grey-Collar' Workers In The People's Republic of China. Human Resource Development International. 12(3):279-296.

Jenkins. C. ve Sherman. B. 1979. The Collapse of Work. Eyre Methuen Press. Hall of Books Shropshire. United Kingdom: London.

Johnson D. B. ve Stern. J. L. 1969. Why and How Workers Shift From Blue-Collar to White-Collar Jobs, Monthly Labor Review 7.

Johnson, D. B ve Stern, J. L 1970. Personnel Journal (Pre-1986); Jun 1970; Proquest Central 49(6): 471.475.

Kalokerinos E.K., Kjelsaast, K., Bennettst, S. ve Hippelt C. 2017. Men In Pink Collars: Stereotype Threat and Disengagement Among Male Teachers and Child Protection Workers. European Journal of Social Psychology. 47:553-565.

Kašč́k, O. Ve Pupala, B. 2013. Buttoning Up The Gold Collar - The Child In Neoliberal Visions of Early Education and Care. Human Affairs. 23:319-337.

Koç, Y. 2013. Türkiye'de İşçi Sınıfı ve Sendikacılık (Dünden Bugüne). Kaynak Yayınları. No:693. İstanbul.

Koçak, O. ve Uygun, B. 2011. Entelektüel Sermayenin Temel Unsuru: Altın Yakalılar. (S. 2764-2773). Saraybosna-Bosna Hersek: Uluslararası 9. Bilgi, Ekonomi ve Yönetim Kongresi Bildirileri.

Kouzmin, A., Korac-Kakabadse, N. ve Korac-Kakabadse, A. 1999. Globalization and Information Technology: Vanishing Social Contracts, The Pink Collar Workforce and Public Policy Challenges. Women In Management Review. 14(6):230-251.

Kraut, R.E. ve Grambsch, P. 1987. Home-Based White Collar Employment: Lessons From The 1980 Census. Social Forces. 66(2):410.

Kudera, W. 1983. Blue Collar-White Collar: Grey Collar? Zum Sozialen Habitus Von Arbeitern Undangestellten In Der Industrie. Soziale Welt. 34(2):201-227.

Landrum, B.A. 1997. Gold Collar Technicians Essential To Chip Industry In Greater Phoenix. Economic Development Review. 15(4):3-7.

Lane, N. 2000. Female Employment In Sales Organisations: Learning To Manage The Pink Collar Army. Joumal of Marketing Management. (16):393-416.

Lebowitz. M. A. 2006. Kapital'in Ötesi Marx ve İşçi Sınıfının Politik İktisadi (Çev. Arif Geniş). Phoenix Yayınları. Ankara.

Lewis, H.G. 1939. The Negro Business, Professional, and White Collar Worker, The Journal of Negro Education. The Present and Future Position of The Negro In The American Social Order (Jul., 1939). 8(3):430-445.

Liben, L.S., Bigler, R.S. ve Krogh H.R. 2001. Pink and Blue Collar Jobs: Children's Judgments of Job Status and Job Aspirations In Relation To Sex of Worker. Journal of Experimental Child Psychology. 79:346-363.

Ling, S., Raine, A., Yang, Y., Schug, R. A., Portnoy, J. ve Ho, R.M. 2018. Increased Frontal Lobe Volume As A Neural Correlate of Gray-Collar offending. Journal of Research In Crime and Delinquency. 20(10):1-34.

Lips-Wiersma, M., Wright, S. ve Dik, B. 2016. Meaningful Work: Differences Among Blue-, Pink-, and White-Collar Occupations. Career Development International Journal. 21(5):534-551.

Malkinson, R; Kushnir, T. ve Weisberg, E. 1997. Stress management and burnout prevention in female blue-collar workers: Theoretical and practical implications. International Journal of Stress Management (Jul 1997). 4(3): 183-195.

Marszalek, B. 2008. Green-Collar Jobs, Industrial Policy, and A Society With A Future. New Labor Forum. 17(3):3137.

Mclaughlin, D.B. 1983. Electronics and The Future of Work: The Impact On Pink and White Collar Workers. The Annals of The American Academy of Political and Social Science. 470:152-162.

Muthuchidambaram. S. 1972. Commitment and Motivation of blue collar workers in İndia. In: Indian Journal of Industrial Relations. 7(4):569-587.

Nakamura. S. K. ve Nakamura M. T. 2000. Increased Risk of Coronary Heart Disease In Japanese Blue-Collar Workers Occupational Medicine. 50(1):11-7.

Pearce ve Stilwell, 2008. Green-Collar Jobs: Employment Impacts of Climate Change Policies. Journal of Australian Political Economy. Review Article: 'Green Collar' Jobs. 62:120-138.

Pennings. J.M. 1970. Work-Value Systems of White-Collar Workers Administrative Science Quarterly. 15(4):397-405.

Pettinger, L. 2017. Green Collar Work: Conceptualizing and Exploring an Emerging Field of Work. Sociology Compass. $11: 1-13$. 
Eriş, E., D., Özmen, Ö., N., T., Bayam, B., Y. / Journal of Yasar University, 2020, 15/58, 259-269

Pinderhughes, R. 2006. Green Collar Jobs: Work Force Opportunities In The Growing Green Economy. Race, Poverty \& The Environment. Getting Ready For Change: Green Economics and Climate Justice (Summer 2006). 13(1):6263.

Punekar. S.D. 1966. Economic and Political Weekly. 1(5):207-208; Sameeksha Trust.

Rachman, D. J. ve Levine, M. 1966. Blue Collar Workers Shape Suburban Markets. Journal of Retailing. Winter66/67, Vol. 42 Issue 4, P5. 10p.

Roe, M.A. 2001. Cultivating The Gold-Collar Worker. Harvard Business Review. May (Electronic Article). https://hbr.org/. Erişim Tarihi: 12.12.18.

Roongrerngsukea, S. ve Liefooghe, A. 2013. Attracting Gold-Collar Workers: Comparing Organizational Attractiveness and Work-Related Values Across Generations In China, India and Thailand. Asia Pacific Business Review. 19(3):337-355

Rung, M.C. 1997. Paternalism and Pink Collars: Gender and Federal Employee Relations, 1941-50. The Business History Review. 71(3):381-416.

Sadler, P. 1994. Gold Collar Workers: What Makes Them Play At Their Best?. Personnel Management. 26(4):28-31.

Seppala, P. 2004. Flat organizations and the role of white-collar employees in production. International Journal of Industrial Ergonomics. 33(1):15-27.

Shear, B.W. 2012. The Green Collar Economy: How One Solution Can Fix Our Two Biggest Problems. Review of Radical Political Economics; 44(1):116-120.

Silberman, C. E. 1965. The Real News About Automation. Fortune, January 1965: 124-126.

Singhvi. S. S. 1993. Time management can boost white-collar productivity. National Productivity Review (Executive Enterprises Publications Co.). 12(4):463-467.

Srivastava A.K.ve Sinha. M. M. 1975. Morale of the Blue-Collar Workers in Relation to Different Degrees of Job Anxiety In: Indian Journal of Industrial Relations. 10(3):371-378.

Sutherland, E. 1940. White Collar Criminality, American Sociological Review. 5(1):1-12.

Şener, M. 2016. Kadınlar Altın Yaka Takabilir Mi? İş Hayatında Eğitimli Kadınlar Için İş Hayatı. Sosyoloji Dergisi. 36:13-40.

Takala, J.; Suwansaranyu, U. and Phusavat, K. 2006. A Proposed White-Collar Workforce Performance Measurement Framework. Industrial Management and Data Systems. 16(5):644-662.

Taylor, R. J. 1995. Canada and The World Backgrounder; Waterloo. 60(5): (Mar 1995).

Tom. C. 1986. The Gold Collar Worker. Southern Economic Journal. 52(4):1196-1187.

Unep. 2008. Green Jobs: Towards Decent Work In A Sustainable, Lowcarbon. United Nations Environment Program.

Wages . . Hours, 1949. "White Collar" Exemption Chart, Labor Law Journal. Nov49, 1(2):144-146.

Walker, C.M. 1996. Financial management, coping and debt in households under financial strain. Journal of Economic Psychology. 17:789-807.

Weaver. C.N. 1975. Job Preferences of White Collar and Blue Collar Workers. The Academy of Management Journal. $18(1): 167-175$

Weber, M. 2003. Sosyoloji Yazıları. Çev: T. Parla, İstanbul İletişim Yayınları. İstanbul.

Wickham, J. 1987. Changing White Collar Work: The office of The Future In Perspective Studies: An Irish Quarterly Review. 76(303):316-325.

Williams, C.L. 1988/90. Blue, White and Pink Collar Workers In Australia: Technicians, Bankemployees and Flight Attendants. Sociology. Allen and Unwin, Sydney. 24(2):300-301.

Williams, C.L. 1993. Doing Women's Work - Men In Nontraditional Occupations, Univercity of Texas-Austin, USA.

Wright, M.C. 2002. White Collar: The American Middle Classes, New York: Oxford University Pres.

Yüksel, Y. 2010. Esnek Kapitalizm ve Altın Yakalı Çalışanlar. İş Ahlakı Dergisi. Turkish Journal of Business Ethics. 3(5):97-117. 